\title{
ESTUDO LEGAL E PRESERVAÇÃO AMBIENTAL DE CÓRREGOS URBANOS EM PRESIDENTE PRUDENTE
}

\author{
Aline Passos Scatalon ${ }^{1}$
}

Arlete Maria Francisco ${ }^{2}$

\begin{abstract}
RESUMO
Este trabalho se propõe a discutir a influência da preservação legal das faixas lindeiras, determinada por meio do Código Florestal de 1965, aos corpos d'água na forma de ocupação de áreas urbanas de fundo de vale, utilizando como estudo de caso dois córregos de Presidente Prudente pertencentes à mesma bacia hidrográfica. Dessa forma, é proposta a realização da análise morfológica das áreas de fundo de vale do Córrego da Colônia Mineira em Presidente Prudente, cuja ocupação aconteceu posteriormente a promulgação da Lei 4.771/65 (Código Florestal). O estudo realizado no Córrego Água Bôscoli será usado como parâmetro de comparação. O objetivo é identificar os diversos tipos de tecidos urbanos existentes, verificando como suas APP foram tratadas e se há diferença no desenho urbano em relação às ocupações anteriores à promulgação da lei, estudadas na primeira etapa da pesquisa. Pretende-se investigar se a obrigatoriedade da preservação dessas áreas, após 1965, garantiu, de fato, que fossem preservadas e que o curso d'água em área urbana pudesse se constituir como elemento da paisagem citadina. Primeiramente, são discutidos os temas referentes à morfologia urbana, posteriormente apresenta um estudo da legislação que trata de APP, com enfoque em suas implicações em meio urbano. Para tal, é apresentado um estudo morfológico das áreas correspondentes aos córregos estudados. Por fim, discute as implicações da legislação e da forma de ocupação nos aspectos gerais dos tecidos urbanos.
\end{abstract}

PALAVRAS-CHAVE: Planejamento Urbano. Áreas de Preservação Permanente. Presidente Prudente, SP.

\section{LEGAL STUDY AND ENVIRONMENTAL PRESERVATION OF URBAN STREAMS IN RESIDENTE PRUDENTE}

\footnotetext{
${ }^{1}$ Discente, FCT/Unesp. alinescatalon@gmail.com.

2 Professor Doutor, FCT/Unesp. arletefrancisco@fct.unesp.br
} 


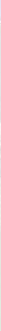

\begin{abstract}
This work aims to discuss the influence of the legal preservation of neighboring bands, determined by the Código Florestal of 1965, to the water bodies in the form of occupation of urban areas in the valley bottom, using as a case study of two streams of Presidente Prudente within the same watershed. Thus, it is proposed to perform the morphological analysis of the areas of valley bottons of the stream Colônia Mineira in Presidente Prudente, whose occupation happened before the enactment of Law 4771/65 (Código Florestal). The study in Stream Água Bôscoli will be used as a comparison parameter. The goal is to identify the various types of existing urban fabric, like checking your APP were treated and whether there are differences in urban design over previous to the enactment of the law, studied in the first stage of the research occupations. It's intend to investigate whether the requirement of preserving these areas after 1965 ensured, in fact, that would be preserved and that the course of water in urban areas could be constituted as part of the cityscape. First, it was discuss the issues related to urban morphology, then presents a study of the legislation that deals with APP, focusing on its implications in the urban environment. For such a morphological study of the corresponding streams studied areas is presented. Finally, it discusses the implications of the legislation and of the occupation in general aspects of the urban fabric.
\end{abstract}

KEY-WORDS: Urban Planning. Permanent Preservation Areas. Presidente Prudente, SP

\title{
ESTUDIO LEGAL Y PRESERVACIÓN AMBIENTAL DE ARROYOS URBANOS EN PRESIDENTE PRUDENTE
}

\begin{abstract}
RESUMEN
Este artículo tiene como objetivo discutir la influencia de la preservación legal de bandas vecinas, determinado por el Código Forestal de 1965, los cuerpos de agua en la forma de ocupación de las zonas urbanas en el fondo del valle, utilizando como estudio de caso de dos corrientes de Presidente prudente dentro de la misma cuenca. Por lo tanto, se propone realizar el análisis morfológico de las zonas de fondo de la Minería Colonia Arroyo en Presidente Prudente valle, cuya ocupación más tarde pasó a la promulgación de la Ley 4771/65 (Código Forestal). El estudio en secuencia del agua Bôscoli ser utilizado como un parámetro de comparación. El objetivo es identificar los distintos tipos de tejido urbano existente, como el control del APP fueron tratados y si existen diferencias en el diseño urbano más anterior a la promulgación de la ley, estudiado en la primera etapa de los trabajos de investigación. Tenemos la intención de investigar si el requisito de conservar estas áreas después de 1965 aseguró, de hecho, que se conserva y que el curso de agua en las zonas urbanas podría constituirse como parte del paisaje urbano. En primer lugar, se discuten los temas relacionados con la morfología urbana, a continuación, se presenta un estudio de la legislación que se ocupa de APP, centrándose en sus implicaciones en el entorno urbano. Para tal estudio morfológico de las zonas corrientes correspondientes estudiados se presenta. Por último, se discuten las implicaciones de la legislación y de la ocupación en los aspectos generales de la trama urbana.
\end{abstract}

PALABRAS-CLAVE: Urbanismo. Áreas de preservación permanente. Presidente Prudente, SP.. 
Estendendo esta ideia para o escopo deste trabalho, o córrego e sua APP, se valorizados, constituir-se-iam em importantes elementos urbanos visíveis e estruturantes da organização física do tecido. A sua relação com outros elementos tipológicos determinariam a forma urbana de uma área. Se esta relação for positiva, teremos como resultado, a "promoção de qualidade físico-ambiental da cidade e dos espaços", defendida por Del Rio (1990, p.177).

Junto ao estudo da morfologia urbana é inerente o estudo a respeito das APP, sobretudo o enfoque dado a essas áreas quando inseridas em meio urbano. De acordo a lei 12.651/2012 ("Novo Código Florestal”) as faixas de APP são delimitadas de acordo com o leito regular e variam conforme a sua dimensão, com largura mínima de 30 metros para cursos d'água de menos de 10 metros de largura, alcançando a marca de 500 metros para cursos d'água de mais de 600 metros de largura.

No entanto, a referida lei passou por algumas modificações até chegar a essas demarcações. A Lei no 4.771/65 considerava a extensão mínima de 5 metros para faixa não edificável marginal aos cursos d'água. Somente em 1986 (Lei 7.511/86), essa faixa é alterada para 30 metros, entretanto, a lei ainda não especificava a partir de que ponto deveria ser medido. Somente na Lei 7.803/89 foi previsto o ponto a partir do qual deveria ser medido a APP: o nível mais alto.

Entretanto, a Lei 6.766/79, ainda vigente, determina uma reserva de faixa mínima de 15 metros para novos parcelamentos urbanos, conflitando com a lei de $12.651 / 2012$.

A promulgação da lei 12.651/12 ("Novo Código Florestal”) revoga o Código Florestal de 65. Neste, é mantida a faixa mínima de 30 metros, porém é alterado do ponto a partir do qual deve ser medido, passando do nível mais alto para ser a partir do leito regular. Para alguns casos, essa modificação faz com que o próprio leito de alguns cursos d'água fique fora da faixa de proteção em épocas de cheia.

Com relação à questão urbana, introduz a regularização fundiária de interesse social e específico dos assentamentos inseridos em áreas urbanas consolidadas que ocupem APP, com base na Lei 11.977/09 (Programa Minha Casa Minha Vida), definindo uma faixa não edificável de 15 metros ao longo do curso d'água (Ramos; Ahmad, 2012). 


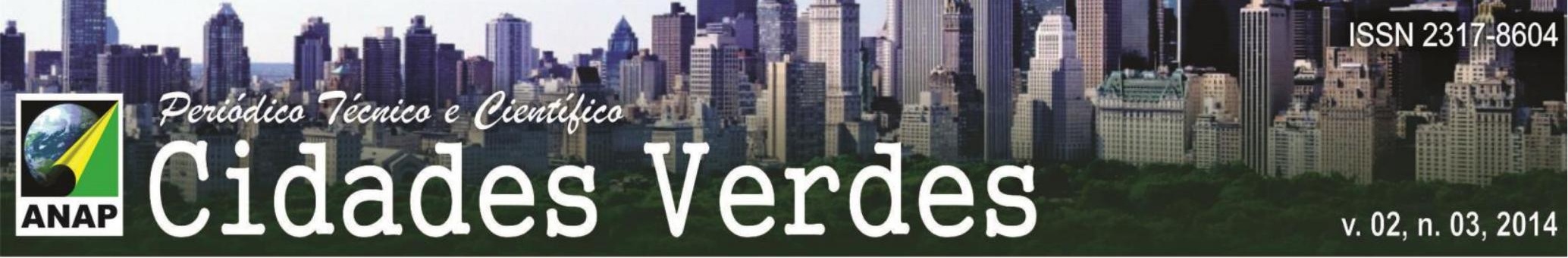

O Estatuto da Cidade (Lei 10.257/01), que tem como principal objetivo garantir a função social da propriedade urbana, também trata da regularização de ocupações irregulares de APP em meio urbano, por meio do Art. $2^{\circ}$, inc. XIV.

A questão que se coloca é qual deve ser a devida consideração referente às áreas de preservação das faixas marginais aos corpos d'água e, principalmente, como conciliar suas funções em relação ao meio urbano. Para Mello (2008, p.94), o conjunto de funções da APP é "instrumento importante para o planejamento urbano e territorial, uma vez que cada uma dessas funções se dá segundo lógicas específicas implicando diferentes condicionantes e requisitos de uso e ocupação do solo".

Existe um cenário de diversas leis que tratam do mesmo assunto e, principalmente, estabelecem metragens diferentes para preservação de várzeas (Fig. 1). Essa divergência abre espaço para que seja usada a lei que se mostre mais vantajosa para o agente explorador do solo e não para o meio ambiente.

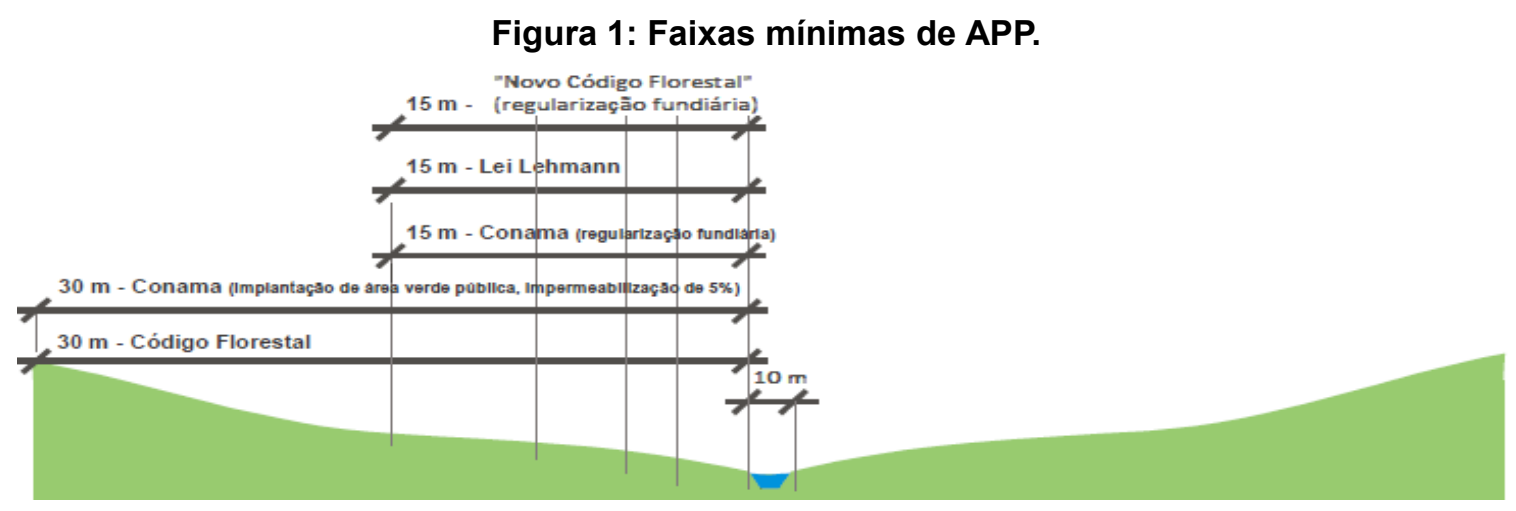

Fonte: Travassos; Grostein (2007). Modificado pela autora.

A ocupação das áreas de fundo de vale tem relação com a legislação. Como a metragem da APP mudou ao longo do tempo, a cada período existia um recorte diferente em função da nova lei que era promulgada. Dessa forma, algumas áreas podem não estar ilegais, porém irregulares de acordo com a legislação atual.

O córrego da Colônia Mineira faz parte da mesma bacia hidrográfica do córrego Água Bôscoli (Fig. 2).

Boa parte do córrego da Colônia Mineira e sua APP foram preservadas no processo de ocupação de sua área, provavelmente devido a sua ocupação ter acontecido em época posterior à promulgação do Código Florestal de 1965 (Fig. 3). 


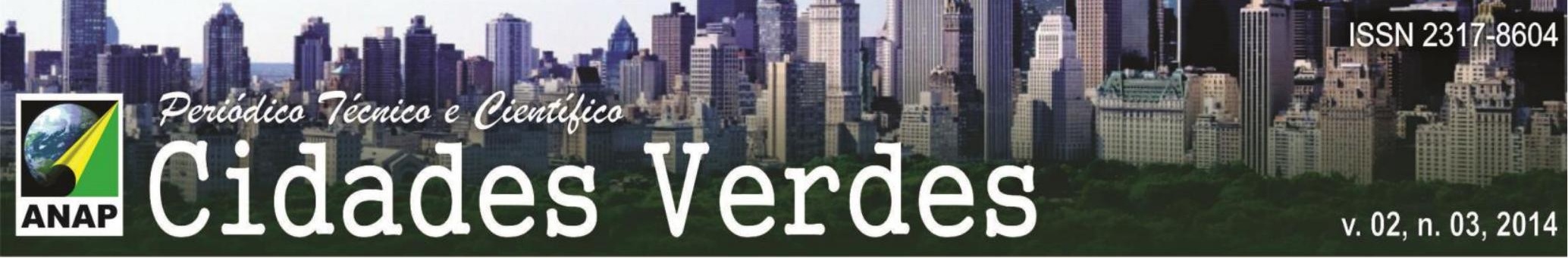

Portanto, ainda é notável nos mapas ou imagens aéreas, já que, por possui área não edificável, deixa seu rastro em meio à cidade. Entretanto, é configurada uma área em meio urbano que não é aproveitada pelo homem. Essa situação que faz com que os córregos sejam vistos como barreiras ao desenvolvimento da cidade, e as áreas residuais se tornem depósito de lixo. Sua reurbanização consistiu na canalização aberta do leito. Antes da canalização, o córrego era utilizado para descarte de resíduos sólidos e líquidos, o que demostra a má relação da população e o corpo d'água. Desse modo, a figura do córrego fica relacionada à sujeira e a população o tratará com descaso, numa situação de abandono. Esse é um dos motivos que conduz para que o tratamento comum do poder público em relação aos córregos urbanos seja a canalização.

Figura 2: Malha urbana e hidrografia de Presidente Prudente, com identificação da bacia de estudo.

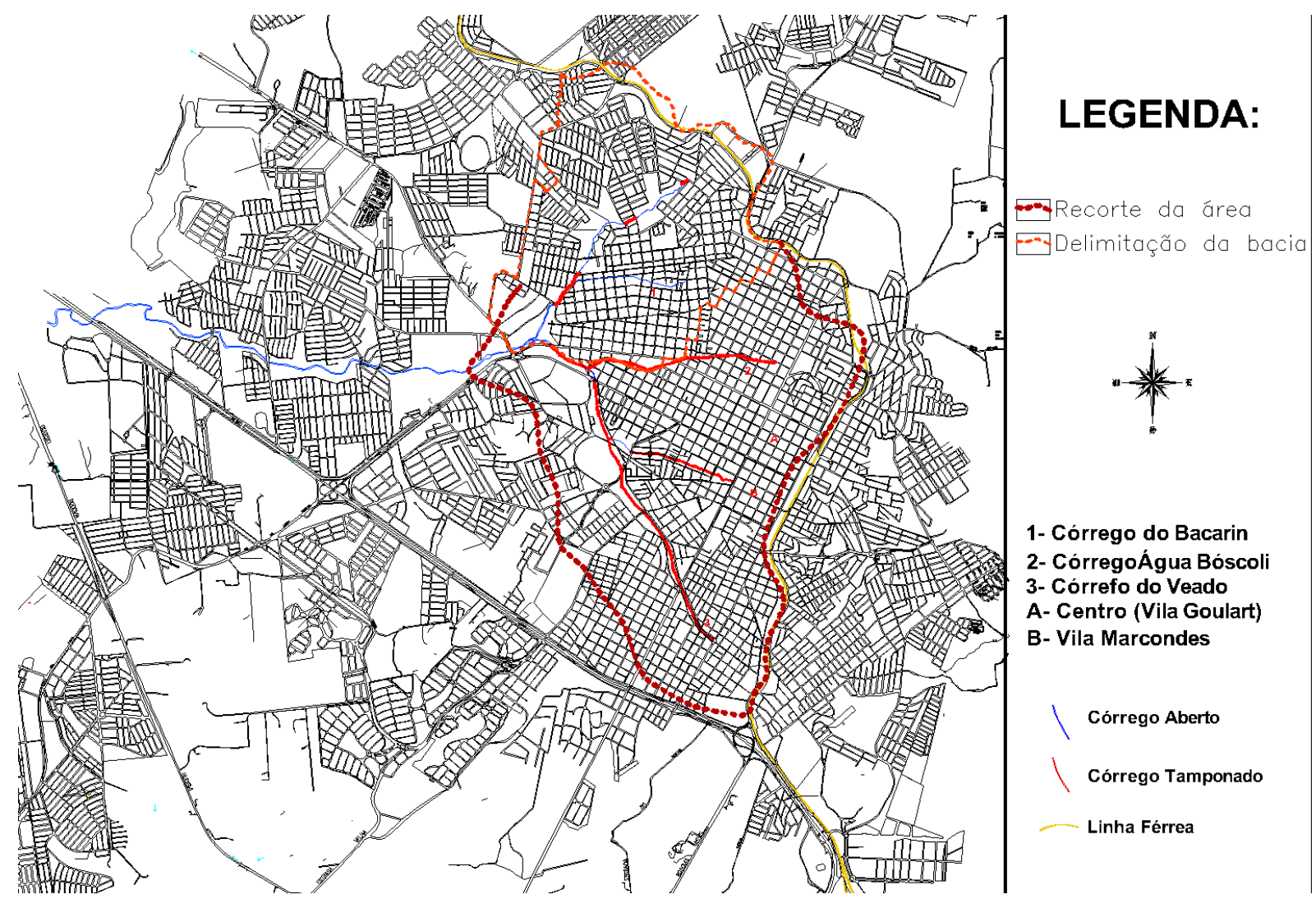

Fonte: Base 10 da Prefeitura Municipal. Modificado pela autora. 


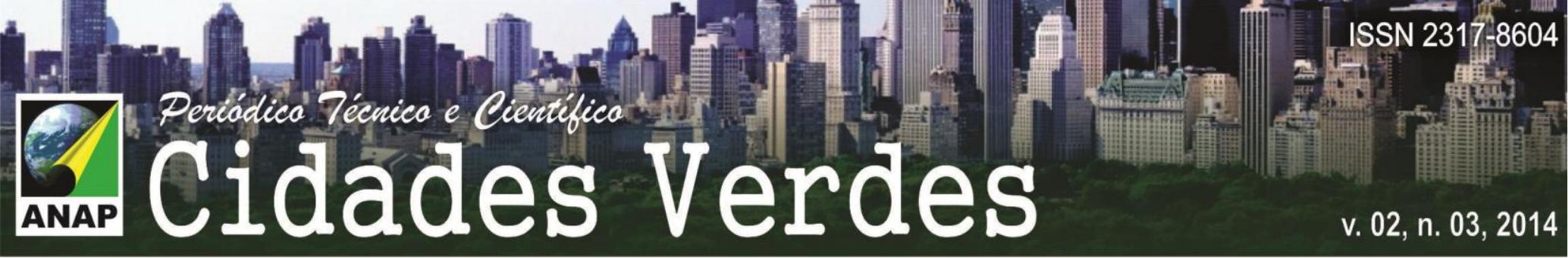

Figura 3: Mapa de crescimento de Presidente Prudente em função da promulgação das leis ambientais que tratam da preservação da APP.

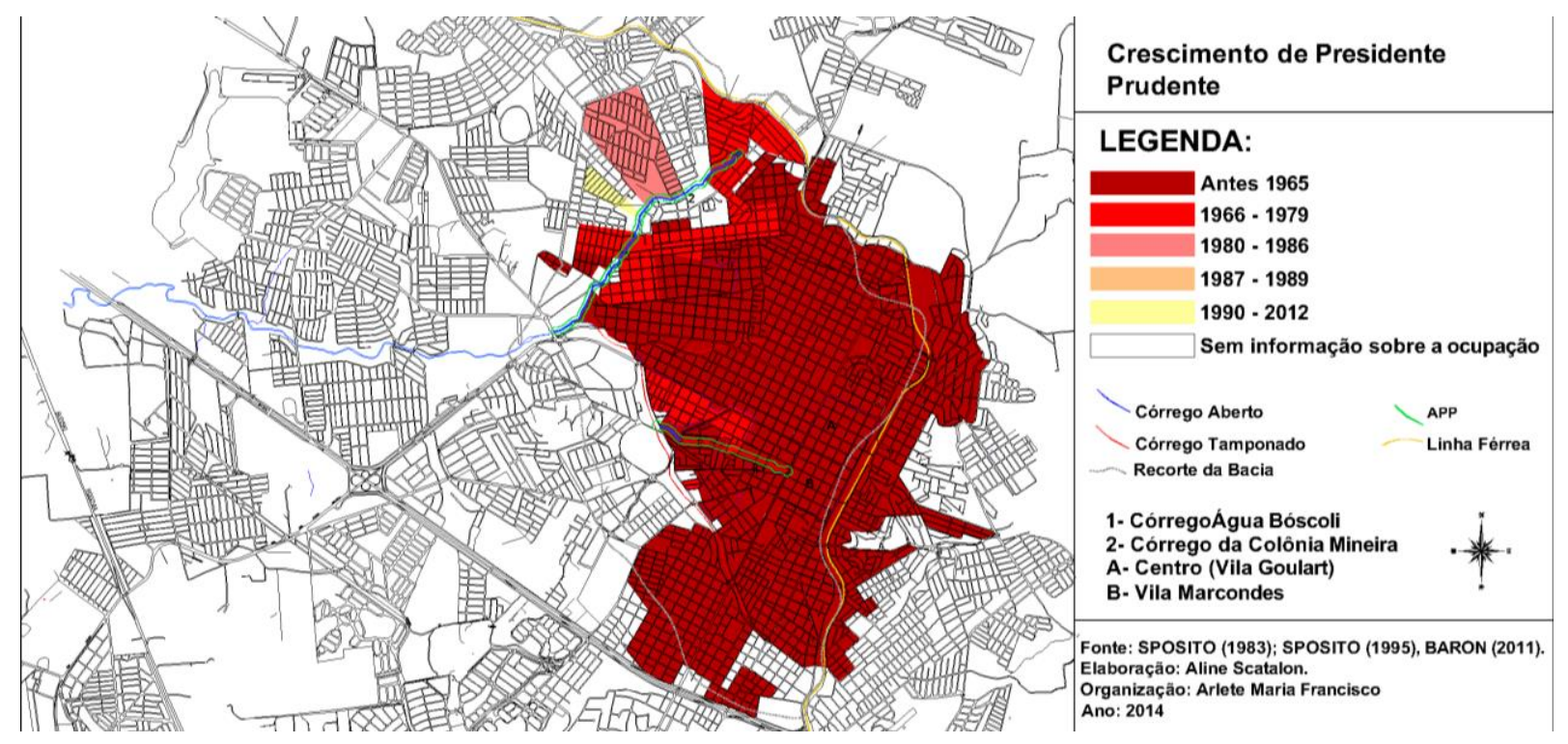

Fonte: SPOSITO (1983), SPOSITO (1995); BARON (2011).

Quanto ao traçado, percebeu-se que o Córrego Água Bôscoli influenciou no desenho na medida em que era uma barreira física no desenho. Dessa forma houve mudança no sentido do traçado dos loteamentos mais próximos ao córrego, devido à sua influencia física. No entanto, não houve consideração quanto ao relevo ou ao corpo d'água como elemento paisagístico incorporador ao desenho da cidade. Por outro lado, por possuir área protegida por lei não edificante à época da ocupação, o Córrego da Colônia Mineira não age como um elemento físico determinador do desenho. Ou seja, o córrego como elemento físico não influência o traçado.

O desenho adquire o traçado não ortogonal na área do Córrego da Colônia Mineira. Esse tipo de traçado propicia um desenho mais coerente com topografia, de modo que são geradas vias com declividades mais coerentes com as recomendadas. No entanto, não é possível atribuir essa inovação no traçado à preservação da APP, sendo mais provável atribuir esse ponto ao fato de que os loteamentos são mais recentes nesta área. 


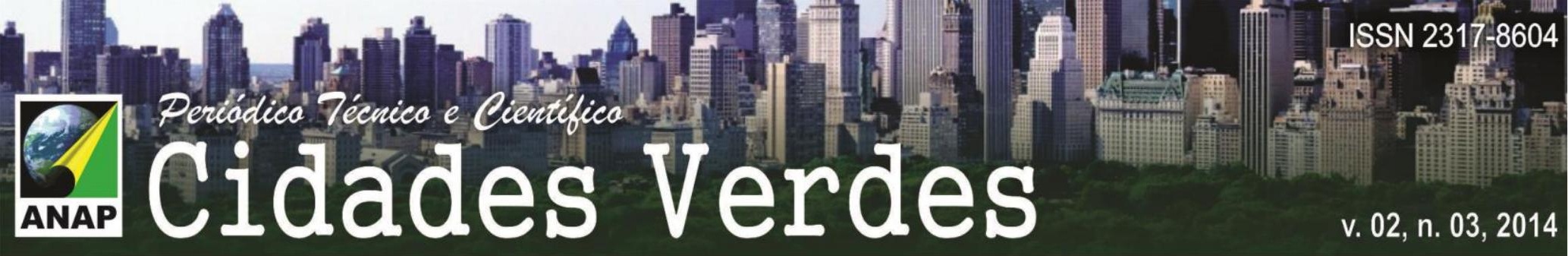

Figura 4: Mapa dos tipos de traçados dos loteamentos adjacentes ao Córrego Água Bôscoli e Colônia Mineira, respectivamente.
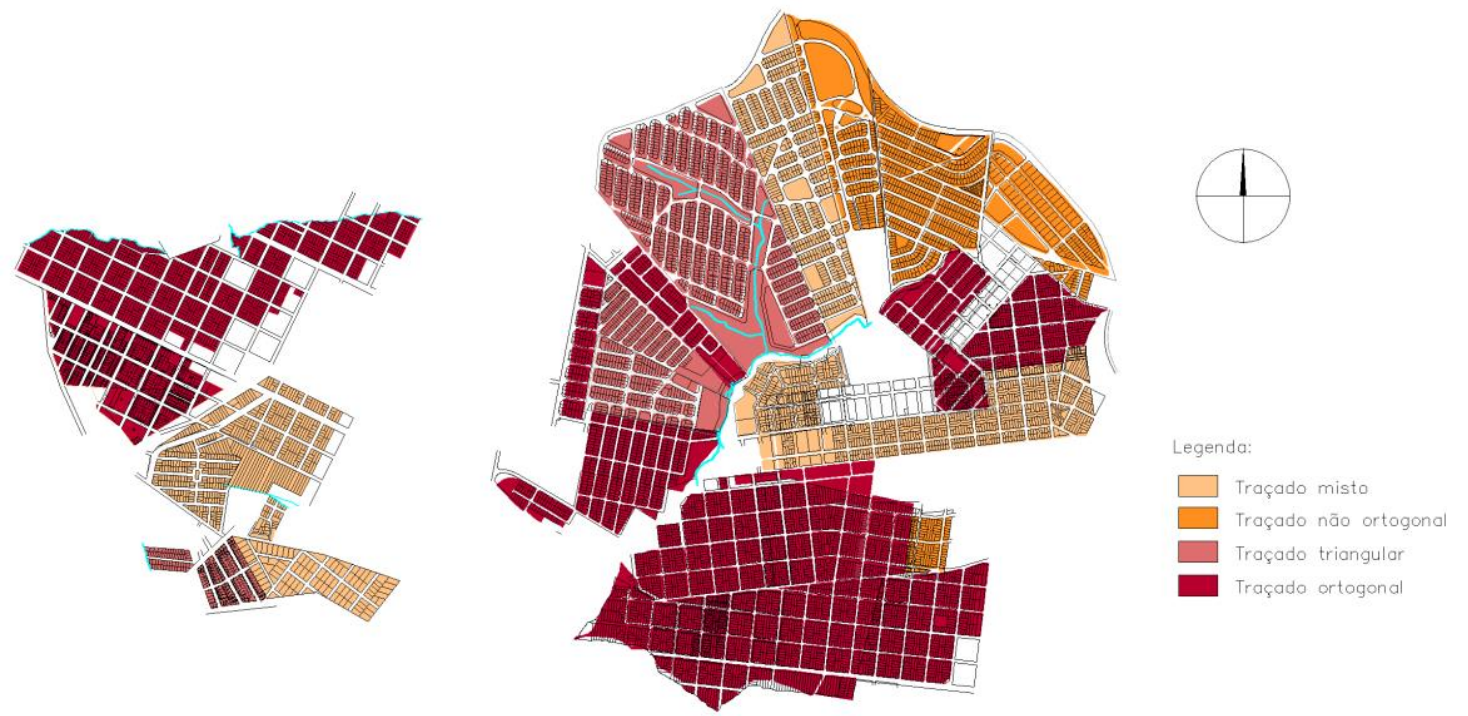

Fonte: Mapas dos loteamentos da prefeitura de Presidente Prudente. Modificado e organizado pela autora.

O processo de urbanização das cidades brasileiras, os rios e os córregos foram vistos como barreiras geográficas a serem superadas e, portanto, como obstáculos para o desenvolvimento urbano. É interessante considerar sua implicação física constituem-se em 'barreiras psicológicas ao crescimento da cidade, devido à dificuldade que impõem à circulação e acesso. Essas áreas podem permanecer vazias enquanto outras bem mais distantes em relação ao centro são ocupadas. (SPOSITO, 1995)

\section{CONCLUSÃO}

A partir do entendimento dos conceitos referentes à Morfologia Urbana foi possível verificar sua importância para compreender a lógica de organização das cidades, mais especificamente, de ocupação das áreas de fundo de vale urbanizadas.

Em meio urbano, a manutenção de uma faixa não edificante ao longo do leito d'água é desejável devido às funções ambientais que exerce. Porém, sem o devido tratamento, em relação ao uso e densidade urbana, se torna uma área abandonada, e por consequência, degradada e mal vista. 
Constatou-se que há uma desarticulação quanto à legislação ambiental e urbanística no tratamento das APP urbanas. Novas soluções devem ser pensadas para resolver o conflito entre preservação e urbanização, isto é, a preocupação ambiental e a preservação dos recursos e, por outro, da cidade e de sua permanente tendência de aglomeração no espaço. As intervenções em várzeas urbanas devem conciliar os valores e funções ambientais e de urbanidade.

Quanto ao desenho, não foi possível identificar que a preservação legal das áreas lindeiras aos córregos gerou uma evolução quanto aos traçados dos loteamentos. Nesse sentido, há um aproveitamento da figura do córrego de modo que ele seja incorporado ao desenho da cidade como elemento paisagístico.

\section{REFERÊNCIAS}

BARON, Cristina Maria P. Habitação e Cidade em Presidente Prudente. 2011. Tese (Doutorado em Arquitetura) - Universidade de São Paulo, São Carlos, 2011.

DEL RIO, J. M. R. G. Introdução do desenho no processo de planejamento. São Paulo: Pini, 1990.

SPOSITO, M. E. B. A Expansão Territorial Urbana de Presidente Prudente. Recortes, No. 4, 61 p., 1995.

MELLO, S. S. Na beira do rio tem uma cidade. Tese de doutorado em Arquitetura e Urbanismo, Faculdade de Arquitetura e Urbanismo, Universidade de Brasília. Brasília: s.n., 2008.

SPOSITO, M. E. B. O “chão” em Presidente Prudente: a lógica de expansão territorial urbana. 1983. Dissertação (mestrado em geografia) - Instituto de Geociências e Ciências Exatas de Rio Claro, Universidade Estadual Paulista "Júlio de Mesquita Filho", Rio Claro, SP, 1983.

SPOSITO, M. E. B. A Expansão Territorial Urbana de Presidente Prudente. Recortes, No. 4, 61 p., 1995.

TRAVASSOS, L.; GROSTEIN, M. D. Instrumentos legais para uso e conservação de várzeas urbanas. In: APPURBANA, II, 2007, São Paulo. Anais. São Paulo: USP, 2007. 